\title{
Cnidaria in UK coastal waters: description of spatio-temporal patterns and inter-annual variability
}

\author{
STEPHEN K. PIKESLEY ${ }^{1,2}$, BRENDAN J. GODLEY ${ }^{1}$, SUE RANGER ${ }^{1,3}$, PETER B. RICHARDSON ${ }^{3}$ \\ AND MATTHEW J. WITT ${ }^{2}$ \\ ${ }^{1}$ Centre for Ecology and Conservation, University of Exeter, Cornwall, TR1o 9EZ, UK, ${ }^{2}$ Environment and Sustainability Institute, \\ University of Exeter, Cornwall, TR10 9EZ, UK, ${ }^{3}$ Marine Conservation Society, Ross on Wye, HR9 7QQ, UK
}

\begin{abstract}
Concern has been expressed over future biogeographical expansion and habitat capitalization by species of the phylum Cnidaria, as this may have negative implications on human activities and ecosystems. There is, however, a paucity of knowledge and understanding of jellyfish ecology, in particular species distribution and seasonality. Recent studies in the UK have principally focused on the Celtic, Irish and North Seas, but all in isolation. In this study we analyse data from a publiclydriven sightings scheme across UK coastal waters (2003-2011; 9 years), with the aim of increasing knowledge on spatial and temporal patterns and trends. We describe inter-annual variability, seasonality and patterns of spatial distribution, and compare these with existing historic literature. Although incidentally-collected data lack quantification of effort, we suggest that with appropriate data management and interpretation, publicly-driven, citizen-science-based, recording schemes can provide for large-scale (spatial and temporal) coverage that would otherwise be logistically and financially unattainable. These schemes may also contribute to baseline data from which future changes in patterns or trends might be identified. We further suggest that findings from such schemes may be strengthened by the inclusion of some element of effort-corrected data collection.
\end{abstract}

Keywords: citizen science, jellyfish, life cycle, public sightings, Scyphozoa, Hydrozoa

Submitted 18 September 2013; accepted 20 January 2014; first published online 4 June 2014

\section{INTRDDUCTION}

The past decade has seen concerns expressed over blooms, future biogeographical expansion and habitat capitalization by pelagic species of the phylum Cnidaria (Mills, 2001; Brodeur et al., 2002; Lynam et al., 2006; Attrill et al., 2007; Purcell et al., 2007; Richardson et al., 2009). Gelatinous plankton (subsequently referred to as jellyfish) blooms in coastal waters can have negative implications for human activities (Purcell et al., 2007; Purcell, 2009), with both social and economic repercussions (Doyle et al., 2007), as well as potential impacts on other species competing for the same habitat (Lynam et al., 2005a).

Fluctuations in jellyfish abundance have potentially been linked with climate indices such as the North Atlantic Oscillation (NAO) and the North Pacific Decadal Oscillation (NPDO) (e.g. Lynam et al., 2004, 2005b; Purcell, 2005) as well as variation in sea surface temperature (SST) (e.g. Lynam et al., 2011), pH (Attrill et al., 2007), salinity (Bastian et al., 2011a), eutrophication (Purcell et al., 2007) and habitat modification (Richardson et al., 2009). Future climate change may modify oceanographic dynamics, thereby further influencing

Corresponding author:

M.J. Witt

Email: M.J.Witt@exeter.ac.uk (positively or negatively) abundance and distribution of marine planktonic communities (Hays et al., 2005). These factors may also be related to increases in abundance associated with opportunistic expansion, following decreased predatory pressure as a result of declining fish abundance due to commercial fisheries (Pauly et al., 1998; Mills, 2001; Lynam et al., 2006).

Large-scale spatial knowledge and understanding of jellyfish ecology is data deficient (Doyle et al., 2007; Purcell, 2009), although local scale insight has improved. For coastal waters of the UK, an extensive review of historic literature ( $\sim 100$ years) (Russell, 1970) exists, and more recently, jellyfish medusae studies have focused on the waters of the Celtic, Irish, and North Seas as well as the Solent estuarine system on the south coast of the UK. These studies have used a variety of methods to obtain data, including: ships of opportunity (Doyle et al., 2007; Bastian et al., 2011a); trawl surveys (primarily as by-catch; Lynam et al., 2005b, 2011; Bastian et al., 2011b); aerial surveys (Houghton et al., 2006a, b; Lilley et al., 2009); electronic tagging (Hays et al., 2011); shoreline surveys (Doyle et al., 2007); and analysis of historical records (Lilley et al., 2009).

Analyses of incidentally-collected sightings/strandings data, from public recording schemes for other marine species, have identified significant spatial and temporal patterns and trends and provided insight into regional and large-scale national distributions (Witt et al., 2007, 2012; Leeney et al., 2008; Pikesley et al., 2012). In the UK, a 
public sightings scheme (http://www.mcsuk.org/sightings/ jellyfish.php) managed by the Marine Conservation Society (MCS), UK, allows members of the public and other interested parties to report sightings and strandings data for eight species of Cnidaria. These include six species of the class Scyphozoa: Aurelia aurita (Linnaeus, 1758) (moon); Cyanea capillata (Linnaeus, 1758) (lion's mane); Chrysaora hysoscella (Linnaeus, 1766) (compass); Cyanea lamarckii (Péron \& Lesueur, 1810) (blue); Pelagia noctiluca (Forsskål, 1775) (mauve stinger) and Rhizostoma octopus (Macri, 1778) (root mouth or barrel); and two species of the class Hydrozoa: Physalia physalis (Linnaeus, 1758) (Portuguese man-of-war); and Velella velella (Linnaeus, 1758) (by-the-wind-sailor). The last two species are not true 'jellyfish' but are included in the MCS 'Jellyfish' Survey data for completeness, as they are occasionally found in coastal waters and on beaches of the UK. As far as we are aware, this database has the largest spatial and temporal coverage for jellyfish sightings in UK coastal waters.

Here we describe spatial and temporal patterns (including seasonal and annual trends) for these eight species of the phylum Cnidaria, across the coastal waters of the UK, between 2003 and 2011 (9 years), as recorded by the MCS UK national 'Jellyfish' Survey database.

\section{MATERIALS AND METHODS}

\section{Data preparation}

The MCS 'Jellyfish' Survey was initiated in 2003 to enhance the understanding of the spatial and temporal patterns of jellyfish occurrence in UK coastal waters, through the recording of sightings and strandings of the adult medusae. The MCS promotes public awareness of this scheme annually, typically at the end of July, through national and regional media releases (newspaper, radio and television). Awareness of the scheme is also furthered by marketing via the MCS website and by distribution of promotional materials, including electronic and hard copy ID cards (Supplementary Figure $\mathrm{S}_{1}$ ). Members of the public were required to submit their written records of sightings and strandings by post, using a standardized form, but this was superseded in 2007 by an on-line submission form.

The MCS UK database held 7229 records (2003-2011). A Geographical Information System (GIS) (ArcMap 10: ESRI, Redlands, US, http://www.esri.com) basemap was used for the UK and Ireland using coordinates conforming to the British National Grid (BNG) projection (metres). The locations of all sightings/strandings, hereafter referred to as sightings, were converted from Ordnance Survey grid references to decimal degree coordinates (longitude, latitude: WGS84); the year and month of occurrence for all sightings were also determined. These location data were added to the basemap, applying a transformation from WGS84 to BNG. These data were then validated as follows. Records without location data and/or date ( $\mathrm{N}=110,1.5 \%$ of records), without species identification $(\mathrm{N}=444,6.1 \%$ of records) were removed. Absence records (no sightings recorded) $(\mathrm{N}=673,9.3 \%$ of records) were removed as there was no record of effort associated with these data and therefore they could not provide a meaningful contribution to the analysis. One individual recorder was identified within the dataset who had contributed data between 2004 and $2009(\mathrm{~N}=951,13.2 \%$ of records $)$ from a single location, Harlech Bay, North Wales, $(\sim 5.5 \mathrm{~km}$ of coastline). As these data, in part, conformed to a pseudostandardized survey method they were removed to minimize bias and analysed separately. In total, 5051 records were retained for eight species of Cnidaria. Each of these remaining records represented single or multiple sightings, beached or at sea.

\section{Statistical analysis}

To investigate any relationship between sightings by year and preceding winter NAO (December, January, February and March) climate indices data were sourced (UCAR, 2013). To contextualize the number of yearly records received in relation to public awareness of the sightings scheme, a measure of yearly promotional effort (number of press hits that publicised the scheme) for printed media (2003 to 2010) was categorized using an ordinal scale of 1 (minimum) to 3 (maximum).

Spearman's rank correlations were calculated to investigate any relationship within our data between sightings by year as a proportion of all sightings and (a) preceding winter NAO and (b) promotional effort of the database. Generalized linear modelling (GLM) was used to investigate species-specific sightings as proportion of all sightings by year. Statistical analysis was undertaken with the program R ( $\mathrm{R}$ Development Core Team, 2008).

To calculate the density of sightings we used a polygon sampling grid, divided by UK regional areas, to sum the coincident length of coastline and sightings locations for each polygon. This enabled us to calculate sightings $\mathrm{km}^{-1}$ for each region. To ascertain a spatial pattern of species richness we used a polygon sampling grid of $50 \times 50 \mathrm{~km}$ squares to sum individual species occurring in each grid square. To investigate the potential for spatial patterns in cnidarian aggregations we used the same polygon sampling grid to sum individual species-specific sightings of 100 Cnidaria or more.

\section{RESULTS}

\section{Temporal variation and species composition}

\section{MAIN DATABASE}

Sightings of jellyfish fluctuated annually, with peak years being 2004, 2005 and 2009 (Figure 1A; Supplementary Figure S2). There was no statistically significant correlation between yearly sightings and promotional effort of the scheme or between yearly sightings and winter NAO. Seasonality was clearly evident, with the number of records peaking in the months of June, July and August (Figure $1 \mathrm{~B}$ ).

The most commonly sighted species was Aurelia aurita $(\mathrm{N}=1460,28.9 \%$ (of validated records)), there were also regular sightings for Cyanea capillata $(\mathrm{N}=920,18.2 \%)$, Chrysaora hysoscella $(\mathrm{N}=955,18.9 \%)$, Cyanea lamarckii $(\mathrm{N}=756,15 \%)$ and Rhizostoma octopus $(\mathrm{N}=483,9.6 \%)$ (Figure ${ }_{1} \mathrm{C}$ ). Of these, $R$. octopus was the only species with year-round presence (Figure $1 \mathrm{D}$ ). The only other scyphozoan or 'true' jellyfish, Pelagia noctiluca was only recorded occasionally $(\mathrm{N}=91,1.8 \%)$, with infrequent sightings (Supplementary Figure $\mathrm{S}_{3} \mathrm{E}$ ). Chrysaora hysoscella sightings significantly decreased during this study $\left(\mathrm{GLM}: \mathrm{F}_{1,7}=12.39\right.$, 

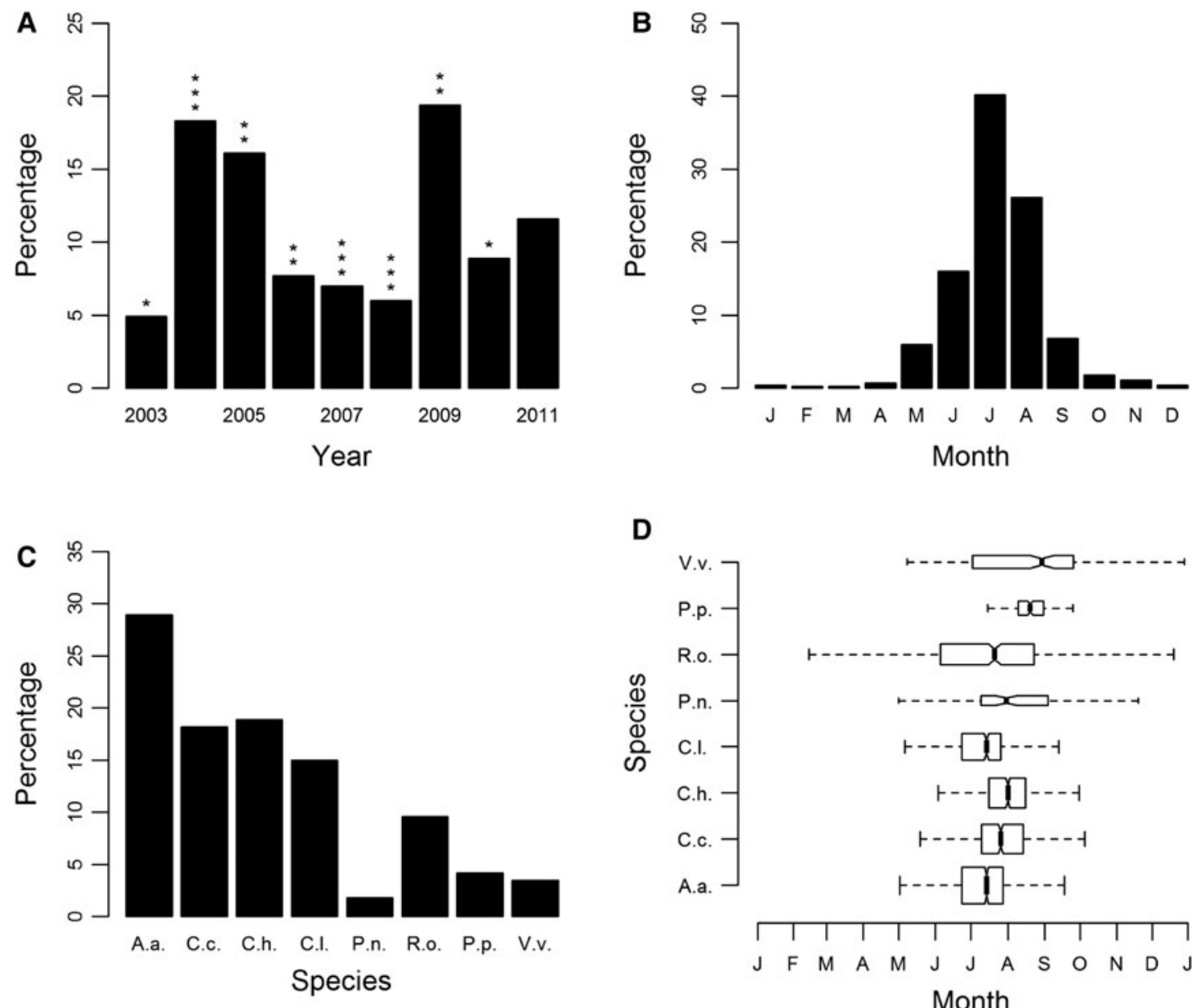

Fig. 1. Sightings for all cnidarian species expressed as a percentage of sightings from 2003 to 2011 (main database): (A) by year; (B) by month; (C) species-specific sightings expressed as a percentage of all sightings from 2003 to 2011 ; (D) species-specific sightings by month. Box shows median and inter-quartile ranges. Box widths are proportional to the square-roots of the number of observations in the box, outliers are not drawn. In (A) asterisks indicate an assessment of the yearly promotional effort of the jellyfish sightings scheme categorized using an ordinal scale of 1 (minimum) to 3 (maximum) promotional effort. In (C) and (D) species are identified as follows: A.a., Aurelia aurita; C.c., Cyanea capillata; C.h., Chrysaora hysoscella; C.l., Cyanea lamarckii; P.n., Pelagia noctiluca; R.o., Rhizostoma octopus; P.p., Physalia physalis; V.v., Velella velella.

$P<0.01$ ); this was the only species for which there was a statistically significant trend. The Hydrozoa, Physalia physalis $(\mathrm{N}=211,4.2 \%)$ and Velella velella $(\mathrm{N}=1753.5 \%)$ were also recorded infrequently with $P$. physalis having a very short sightings season (Figure $1 \mathrm{D}$ ), with the vast majority of sightings occurring in 2008 and 2009; $93 \%$ of all $P$. physalis records were attributable to these years (Supplementary Figure $\left.\mathrm{S}_{3} \mathrm{G}\right)$.

\section{HARLECH BAY DATABASE}

Peak years for sightings of jellyfish from Harlech Bay (location map: inset Figure 2C) were 2004, 2005 and 2006; records of sightings were lower for 2007, 2008 and 2009. There were no sightings data available for 2003,2010 or 2011 (Figure 2A). Seasonality was clearly evident with the number of records peaking in the months of June and July (Figure $2 \mathrm{~B}$ ).

The most commonly sighted species was $R$. octopus $(\mathrm{N}=$ 499, $52.5 \%$ (of validated records)) (Figure $2 \mathrm{C}$ ). Five other species were regularly sighted: A. aurita $(\mathrm{N}=139,14.6 \%)$; C. capillata $(\mathrm{N}=95,10 \%) ; C$. hysoscella $(\mathrm{N}=86,9 \%) ; C$. lamarckii $(\mathrm{N}=100,10.5 \%)$; and $V$. velella $(\mathrm{N}=32,3.4 \%)$. Of these, $R$. octopus and $V$. velella were sighted throughout the year (Figure 2D). There was a marked decrease in the proportion of R. octopus sightings in 2008 and 2009, $20 \%$ and $33 \%$ of annual sightings, respectively, compared with the peak year for $R$. octopus sightings 2006, 63\% of annual sightings (Supplementary Figure $\mathrm{S}_{4} \mathrm{E}$ ). There were no recorded sightings for $P$. noctiluca or $P$. physalis (Figure 2D).

\section{Spatial distribution}

Within the main database for UK coastal waters (excluding the Republic of Ireland) the greatest number of sightings were from western shores (Figure $3 \mathrm{~A}$; Table 1 ). The southwest had the highest density of sightings (o. 64 sightings $\mathrm{km}^{-1}$ ), higher than the north-east ( 0.22 sightings $\left.\mathrm{km}^{-1}\right)$, the northwest (including Northern Ireland) (0.15 sightings $\mathrm{km}^{-1}$ ) and the south-east, which presented the lowest (0.13 sightings $\mathrm{km}^{-1}$ ); species richness was also greatest in the south-west (Figure 4A). The Bristol Channel had the highest incidence of species-specific cnidarian aggregations (Figure $4 \mathrm{~B}$ ).

Of the most commonly sighted species, $A$. aurita were ubiquitously distributed (Figure $3 \mathrm{~B}$ ), C. capillata and C. hysoscella had a clear north/south divide in their distributions (Figure $\left.{ }_{3} \mathrm{C}, \mathrm{D}\right)$ and $C$. lamarckii had a greater number of sightings 

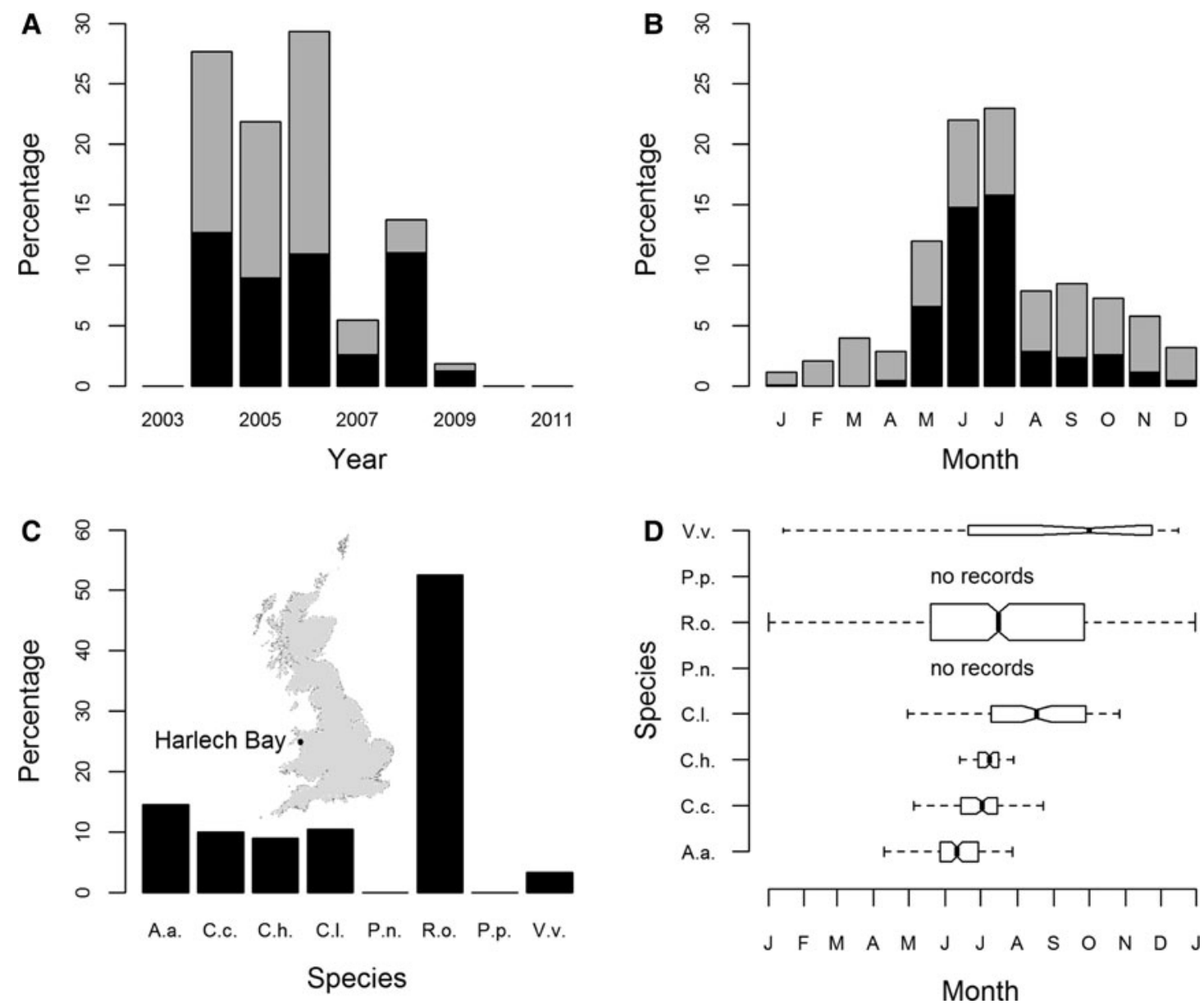

Fig. 2. Sightings for all cnidarian species expressed as a percentage of sightings from 2004 to 2009 (Harlech Bay database); (A) by year; (B) by month; (C) species-specific sightings expressed as a percentage of all sightings from 2004 to 2009; (D) species-specific sightings by month. Box widths are proportional to the square-roots of the number of observations in the box, outliers are not drawn. In (A) and (B) R. octopus sightings are shown as mid-grey, all other species as black. In (C) and (D) species are identified as in Figure 1. The inset in part (C) shows the location of Harlech Bay in relation to the UK.

to the south-west and north-east (Figure $3 \mathrm{E}$ ). The key areas for sightings of $R$. octopus were the coastal waters of Wales and western Scotland (Figure $3 \mathrm{G}$ ). Pelagia noctiluca, P. physalis and $V$. velella were predominantly sighted to the south and west of the UK (Figure $3 \mathrm{~F}, \mathrm{H}, \mathrm{I}$ ).

\section{DISCUSSIDN}

Six species of scyphomedusae are indigenous to UK coastal waters (Russell, 1970). A typical scyphozoan life cycle results in adult medusae being present in the water column during the summer months (Figure 5). The presence of adult medusae then characteristically decreases through the autumn once eggs or planulae have been released. With the exception of the holopelagic Pelagia noctiluca, a suitable shallow, shaded, benthic substrata is required for attachment of these planulae and further development of the scyphistoma (Russell, 1970). Both the main sightings database and the Harlech Bay subset reflected this life cycle, with seasonality of sightings of adult medusae clearly evident. The majority of Scyphozoa sightings occurred in the months of June, July and August; Aurelia aurita and Cyanea lamarckii appeared earlier in the season than Cyanea capillata and Chrysaora hysoscella, similar patterns have been previously recorded (e.g. Doyle et al., 2007; Bastian et al., 2011a). Rhizostoma octopus had the longest sighting season of all Scyphozoa, which may be attributable to this species surviving into winter at greater depths (Russell, 1970). The seasonality of $R$. octopus sightings also reflected previous studies (Doyle et al., 2007).

Seasonality of Hydrozoa sightings varied considerably. Within the main database Velella velella were sighted March to January whereas Physalia physalis were predominantly sighted in late August, this was driven by mass sightings events in 2008 and 2009. Within the Harlech Bay data, sightings of $V$. velella were recorded throughout the year; no sightings were recorded for $P$. physalis. This lack of sightings for $P$. physalis seems contradictory, as both $V$. velella and $P$. physalis are oceanic, surface free-floating species, and therefore their distribution has the potential to be driven by prevailing wind conditions. Velella velella and P. physalis had similar spatial distribution patterns, with the majority of sightings from south-west shores. However, closer inspection revealed that $P$. physalis tended to be concentrated to the south of this region and $V$. velella to the north. This fine-scale nuance in distribution may be an artefact of $P$. physalis sightings being associated with the mass sightings events of 2008 and 2009.

There was no clear temporal trend in annual cnidarian sightings within the main database or the Harlech Bay 

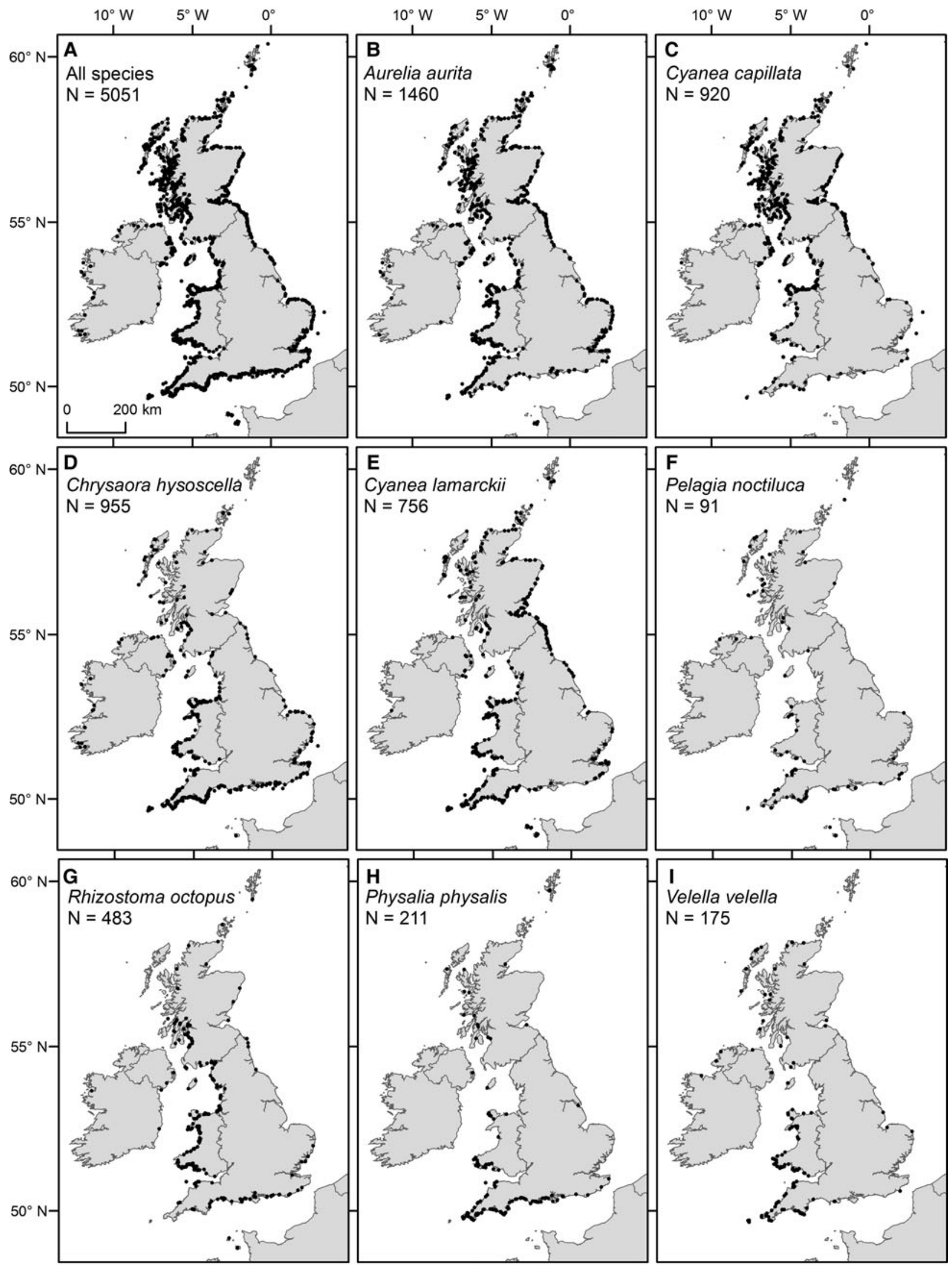

Fig. 3. Spatial distribution of sightings from 2003 to 2011 (main database), for (A) all species and (B-I) specified species, as detailed in figure parts. 
Table 1. Cnidaria sightings for UK coastal regions as defined in Figure $4 \mathrm{~B}$.

\begin{tabular}{lcll}
\hline UK region & Total sightings & $\begin{array}{l}\text { Coastal } \\
\text { length }(\mathbf{k m})\end{array}$ & $\begin{array}{l}\text { Sightings } \\
\left(\mathbf{k m}^{-\mathbf{1}}\right)\end{array}$ \\
\hline $\begin{array}{l}\text { North-east } \\
\text { North-west (including }\end{array}$ & 763 & 3480 & 0.22 \\
$\quad$ Northern Ireland) & & 9381 & 0.15 \\
$\begin{array}{l}\text { South-east } \\
\text { South-west }\end{array}$ & 453 & 3391 & 0.13 \\
\hline
\end{tabular}

subset; however, sightings from Harlech Bay decreased between 2007 and 2009. This decrease may be attributable to a diminished survey effort, although preceding years represented near continuous survey effort (MCS, personal communication). The main database showed inter-annual variability with notable peaks and troughs. There was no correlation between these and promotional effort of the sightings scheme or NAO. Timing and periodicity of recruitment of planulae to the seabed depends on a number of biotic and abiotic factors, such as sexual maturation and reproductive strategy of the medusa, water temperature and turbulence, and physical characteristics of the substratum (Lucas, 2001). Subsequent development of the scyphistoma (budding/ strobilation), has been linked with factors such as temperature, salinity, light intensity and photoperiod (e.g. Purcell,

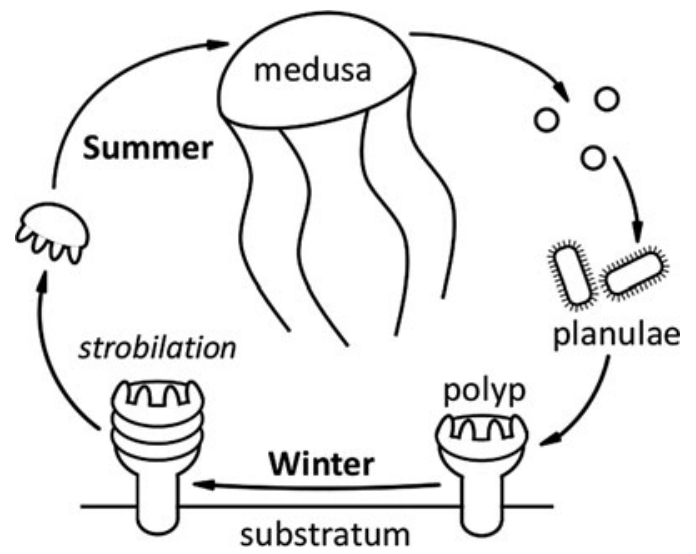

Fig. 5. A typical Scyphozoa life cycle. A suitable shallow, shaded, benthic substrata is required for attachment of planulae and further development of the scyphistoma. Note: Pelagia noctiluca is an oceanic species with direct development and has no benthic stage; C. hysoscella is a hermaphrodite (Russell, 1970).

2007), dissolved oxygen concentrations (Condon et al., 2001) and prey availability (Han \& Uye, 2010). Inter-annual variability may also be driven by hydroclimatic forcing such as wind stress, temperature or currents (Lynam et al., 2004) or through transition in climate regimes (Brodeur et al., 2008). There is also evidence for contrasting relationships
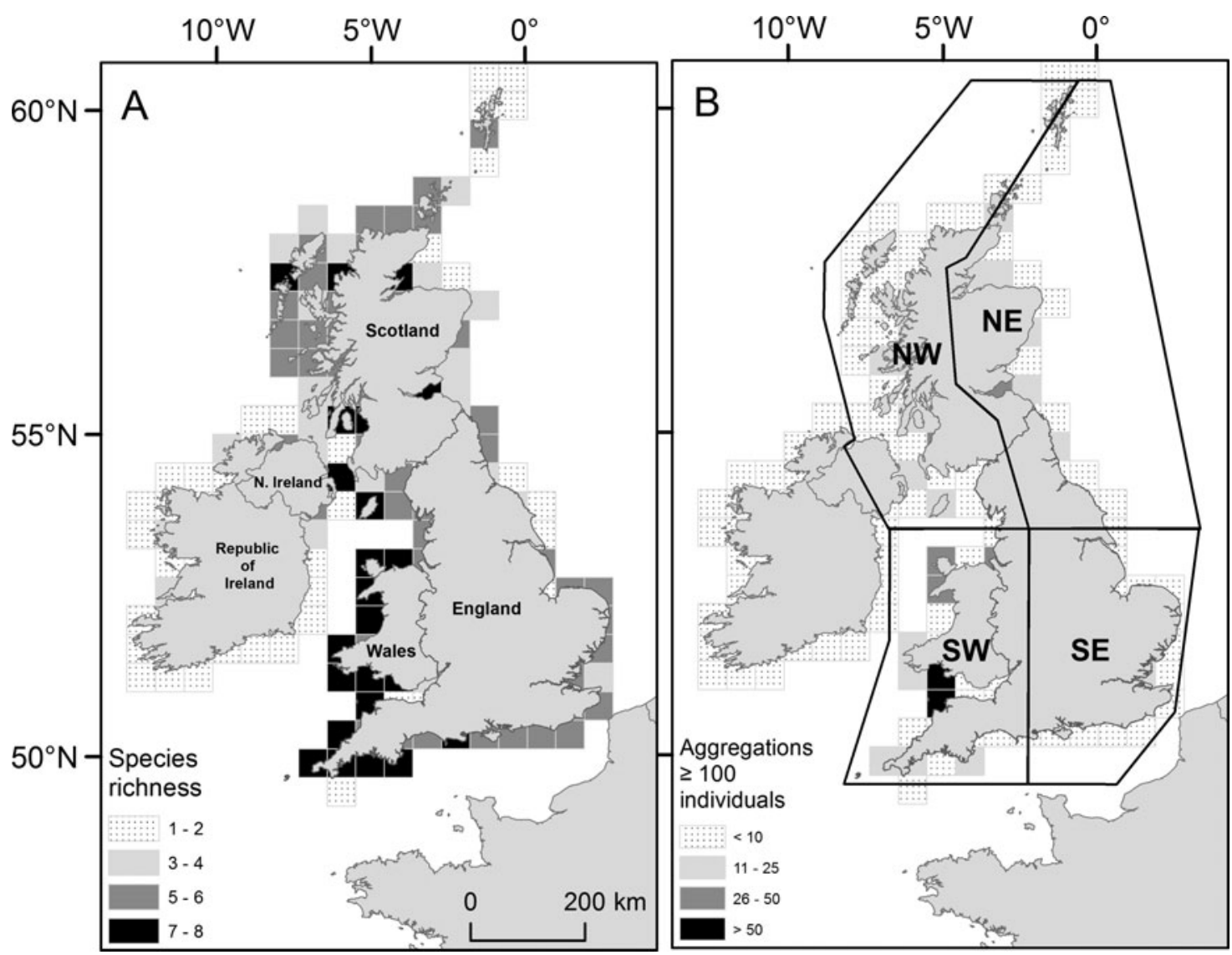

Fig. 4. (A) Species richness for Cnidaria sighted from 2003 to 2011 (main database) in UK coastal waters. Total number of individual species present summed by a $50 \times 50 \mathrm{~km}$ sampling grid; (B) Cnidaria aggregations for UK coastal waters from 2003 to 2011 (main database). Species-specific sightings of 100 Cnidaria or more were summed using the same sampling grid as in (A). (A) and (B) are displayed in accordance with their respective monochrome shaded legend. UK regional areas are drawn in part (B): north-west (NW); north-east (NE); south-east (SE); and south-west (SW). 
between climate indices and Scyphozoa abundance that may also be related to locally variable oceanographic parameters (Lynam et al., 2005b, 2011; Attrill et al., 2007). As this study holds records for multiple species over a wide spatial extent, it is unlikely that one environmental or biological parameter can explain variability in temporal trends. The observed patterns are likely manifest from environmental forcing resulting in a combination of environmental and biological drivers influencing species biology.

Species-specific inter-annual variability was also evident, and the records of no one cnidarian species displayed a uniform temporal pattern. There was a significant decreasing trend for C. hysoscella. However, our data spans a short timeframe ( 9 years) and this trend may not be representative of long-term trends. Indeed, evidence exists for worldwide oscillations in jellyfish populations of approximate 20 year periodicity (Condon et al., 2013). However, robust detection of trends in jellyfish populations are hampered by a lack of a defined baseline; more specifically there is a paucity of longterm data sets, $>20$ years (Condon et al., 2012).

The south-west region had the highest number of sightings (and greatest coastline densities), greatest species richness, and also had the highest incidence of cnidarian aggregations. Aurelia aurita were universally distributed throughout the regions with highest abundance of all species, this is recognized as a cosmopolitan species (Russell, 1970; Lucas, 2001). However, there were clear geographical demarcations between some species; C. hysoscella were nearly always observed in southerly waters, whereas $C$. capillata were sighted in northerly waters. This spatial delineation probably reflects the availability of suitable thermal niches for these species (Holst, 2012). Rhizostoma octopus were principally sighted in coastal waters of western Scotland and Wales. The Harlech Bay database identified this area as a hotspot for $R$. octopus, with this species accounting for $57 \%$ of all sightings between 2004 and 2007, although there was a marked decrease of sightings during 2008/2009, the reason for which is unclear. Pelagia noctiluca were primarily sighted in south-west and north-west waters. There were no sightings from Harlech Bay. This is an oceanic species with direct development (no benthic life cycle stage), and is previously described as occurring off western shores in association with oceanic waters (Russell, 1970). The distribution patterns for $V$. velella and $P$. physalis were comparable to each other, with the majority of sightings from south-west shores. As south-westerly winds prevail for winter, summer and autumn across the UK (Lapworth \& McGregor, 2008) these spatial patterns potentially reflect the wind conditions at the time, driving the distribution of these free-floating surface species.

Without quantification of sightings effort, analysis of incidentally collected data should be made cautiously. However, data collected through citizen-science schemes can provide a valuable resource (Silvertown, 2009), and with appropriate care, these data can provide an insight into species' regional and national patterns and trends (Pikesley et al., 2012; Witt et al., 2012). In this study, incidentally-collected data for cnidarian species have been seen to reflect previouslydocumented temporal and spatial patterns. In addition, data collected from a single location over a significant timescale have revealed location-specific trends.

Although studies of this nature may not be able to isolate the drivers behind observed patterns, they can provide for large-scale (spatial and temporal) coverage that would otherwise be logistically and financially unfeasible. We also suggest that they have the potential to contribute significantly to baselines, providing both seasonality and distribution data (particularly when data are derived from survey schemes that are ongoing), from which future changes in patterns or trends may be identified. The likelihood of important insights being more robustly elaborated would be greatly increased by the incorporation of focused, effort-corrected surveys at locations along the UK coastline, including all nil returns, in at least some locations across the geographical footprint of the project.

\section{ACKNOWLEDGEMENTS}

The authors thank Derryck Greenwood and all participants in the Marine Conservation Society (MCS) jellyfish survey who generously contributed their data. The authors acknowledge the constructive input from two anonymous referees and the Associate Editor.

\section{FINANCIAL SUPPORT}

This work was funded by MCS. B.J.G. receives funding from the EU (Interreg 3a-MERiFIC; Intelligent Energy SOWFIA; European Social Fund) and the Natural Environment Research Council.

\section{Supplementary materials and methods}

The supplementary material refered to in this paper can be found online at journals.cambridge.org/mbi.

\section{REFERENCES}

Attrill M.J., Wright J. and Edwards M. (2007) Climate-related increases in jellyfish frequency suggest a more gelatinous future for the North Sea. Limnology and Oceanography 52, 480-485.

Bastian T., Haberlin D., Purcell J.E., Hays G.C., Davenport J., McAllen R. and Doyle T.K. (2011a) Large-scale sampling reveals the spatiotemporal distributions of the jellyfish Aurelia aurita and Cyanea capillata in the Irish Sea. Marine Biology 158, 2639-2652.

Bastian T., Stokes D., Kelleher J.E., Hays G.C., Davenport J. and Doyle T.K. (2011b) Fisheries bycatch data provide insights into the distribution of the mauve stinger (Pelagia noctiluca) around Ireland. ICES Journal of Marine Science 68, 436-443.

Brodeur R.D., Decker M.B., Ciannelli L., Purcell J.E., Bond N.A., Stabeno P.J., Acuna E. and Hunt Jr G.L. (2008) Rise and fall of jellyfish in the eastern Bering Sea in relation to climate regime shifts. Progress in Oceanography 77, 103-111.

Brodeur R.D., Sugisaki H. and Hunt Jr G.L. (2002) Increases in jellyfish biomass in the Bering Sea: implications for the ecosystem. Marine Ecology Progress Series 233, 89-103.

Condon R.H., Decker M.B. and Purcell J.E. (2001) Effects of low dissolved oxygen on survival and asexual reproduction of scyphozoan polyps (Chrysaora quinquecirrha). Hydrobiologia 451, 89-95.

Condon R.H., Duarte C.M., Pitt K.A., Robinson K.L., Lucas C.H., Sutherland K.R., Mianzan H.W., Bogeberg M., Purcell J.E., Decker M.B., Uye S., Madin L.P., Brodeur R.D., Haddock S.H.D., 
Malej A., Parry G.D., Eriksen E., Quiñones J., Acha M., Harvey M., Arthur J.M. and Graham W.M. (2013) Recurrent jellyfish blooms are a consequence of global oscillations. Proceedings of the National Academy of Sciences of the United States of America 110, 1000-1005.

Condon R.H., Graham W.M., Duarte C.M., Pitt K.A., Lucas C.H., Haddock S.H.D., Sutherland K.R, Robinson K.L, Dawson M.N., Decker M.B., Mills C.E, Purcell J.E, Malej A., Mianzan H., Uye S., Gelcich S. and Madin L.P. (2012) Questioning the rise of gelatinous zooplankton in the world's oceans. BioScience 62, 160-169.

Doyle T.K., Houghton J.D., Buckley S.M., Hays G.C. and Davenport J. (2007) The broad-scale distribution of five jellyfish species across a temperate coastal environment. Hydrobiologia 579, 29-39.

Han C.-H. and Uye S. (2010) Combined effects of food supply and temperature on asexual reproduction and somatic growth of polyps of the common jellyfish Aurelia aurita s.l. Plankton and Benthos Research 5 , $98-105$.

Hays G.C., Bastian T., Doyle T.K., Fossette S., Gleiss A.C., Graveno M.B., Hobson V.J., Humphries N.E., Lilley M.K., Pade N.G. and Sims D.W. (2011) High activity and Lévy searches: jellyfish can search the water column like fish. Proceedings of the Royal Society, $B$ 279, $465-473$

Hays G.C., Richardson A.J. and Robinson C. (2005) Climate change and marine plankton. Trends in Ecology and Evolution 20, 337-344.

Holst S. (2012) Effects of climate warming on strobilation and ephyra production of North Sea scyphozoan jellyfish. Hydrobiologia 690, 1-14.

Houghton J.D., Doyle T.K., Davenport J. and Hays G.C. (2006a) The ocean sunfish Mola mola: insights into distribution, abundance and behaviour in the Irish and Celtic Seas. Journal of the Marine Biological Association of the United Kingdom 86, 1237-1243.

Houghton J.D., Doyle T.K., Wilson M.W., Davenport J. and Hays G.C. (2006b) Jellyfish aggregations and leatherback turtle foraging patterns in a temperate coastal environment. Ecology 87, 1967-1972.

Lapworth A. and McGregor J. (2008) Seasonal variation of the prevailing wind direction in Britain. Weather 63, 365-368.

Leeney R.H., Amies R., Broderick A.C., Witt M.J., Loveridge J., Doyle J. and Godley B.J. (2008) Spatio-temporal analysis of cetacean strandings and bycatch in a UK fisheries hotspot. Biodiversity and Conservation 17, 2323-2338.

Lilley M.K.S., Houghton J.D.R. and Hays G.C. (2009) Distribution, extent of inter-annual variability and diet of the bloom-forming jellyfish Rhizostoma in European waters. Journal of the Marine Biological Association of the United Kingdom 89, 39-48.

Lucas C.H. (2001) Reproduction and life history strategies of the common jellyfish, Aurelia aurita, in relation to its ambient environment. Hydrobiologia 451, 229-246.

Lynam C.P., Gibbons M.J., Axelsen B.E., Sparks C.A., Coetzee J., Heywood B.G. and Brierley A.S. (2006) Jellyfish overtake fish in a heavily fished ecosystem. Current Biology 16, 492.

Lynam C.P., Hay S.J. and Brierley A.S. (2004) Interannual variability in abundance of North Sea jellyfish and links to the North Atlantic Oscillation. Limnology and Oceanography 49, 637-643.

Lynam C.P., Hay S.J. and Brierley A.S. (2005b) Jellyfish abundance and climatic variation: contrasting responses in oceanographically distinct regions of the North Sea, and possible implications for fisheries. Journal of the Marine Biological Association of the United Kingdom $85,435-450$
Lynam C.P., Heath M.R., Hay S.J. and Brierley A.S. (2005a) Evidence for impacts by jellyfish on North Sea herring recruitment. Marine Ecology Progress Series 298, 157-167.

Lynam C.P., Lilley M.K.S., Bastian T., Doyle T.K., Beggs S.E. and Hays G.C. (2011) Have jellyfish in the Irish Sea benefited from climate change and overfishing? Global Change Biology 17, 767-782.

Mills C.E. (2001) Jellyfish blooms: are populations increasing globally in response to changing ocean conditions? Hydrobiologia 451, 55-68.

Pauly D., Christensen V., Dalsgaard J., Froese R. and Torres Jr F. (1998) Fishing down marine food webs. Science 279, 860-863.

Pikesley S.K., Witt M.J., Hardy T., Loveridge J., Loveridge J., Williams R. and Godley B.J. (2012) Cetacean sightings and strandings: evidence for spatial and temporal trends? Journal of the Marine Biological Association of the United Kingdom 92, 1809-1820.

Purcell J.E. (2005) Climate effects on formation of jellyfish and ctenophore blooms: a review. Journal of the Marine Biological Association of the United Kingdom 85, 461-476.

Purcell J.E. (2007) Environmental effects on asexual reproduction rates of the scyphozoan Aurelia labiata. Marine Ecology Progress Series 348, $183-196$.

Purcell J.E. (2009) Extension of methods for jellyfish and ctenophore trophic ecology to large-scale research. Hydrobiologia 616, 23-50.

Purcell J.E., Uye S.-I. and Lo W.-T. (2007) Anthropogenic causes of jellyfish blooms and their direct consequences for humans: a review. Marine Ecology Progress Series 350, 153-174.

R Development Core Team (2008) R: A language and environment for statistical computing. Vienna: $\mathrm{R}$ Foundation for Statistica Computing. Available at: http://www.Rproject.org (accessed 8 May 2014).

Richardson A.J., Bakun A., Hays G.C. and Gibbons M.J. (2009) The jellyfish joyride: causes, consequences and management responses to a more gelatinous future. Trends in Ecology and Evolution 24, $312-322$.

Russell F.S. (1970) The medusae of the British Isles II. Pelagic Scyphozoa with a supplement to the first volume on hydromedusae. Cambridge: Cambridge University Press.

Silvertown J. (2009) A new dawn for citizen science. Trends in Ecology and Evolution 24, 467-471.

UCAR (2013) Hurrell PC-Based North Atlantic Oscillation Index (Monthly). https://climatedataguide.ucar.edu/climate-data/hurrell-northatlantic-oscillation-nao-index-pc-based (accessed 4 March 2013).

Witt M.J., Broderick A.C., Johns D.J., Martin C., Penrose R., Hoogmoed M.S. and Godley B.J. (2007) Prey landscapes help identify potential foraging habitats for leatherback turtles in the NE Atlantic. Marine Ecology Progress Series 337, 231-243.

and

Witt M.J., Hardy T., Johnson L., McClellan C.M., Pikesley S.K., Ranger S., Richardson P.B., Solandt J.-L., Speedie C. and Williams R. (2012) Basking sharks in the northeast Atlantic: spatio-temporal trends from sightings in UK waters. Marine Ecology Progress Series 459, 121-134.

\section{Correspondence should be addressed to:}

M.J. Witt

Environment and Sustainability Institute, University of Exeter Penryn Campus, Treliever Road Penryn, Cornwall. TR1o 9EZ, UK email: M.J.Witt@exeter.ac.uk 